\title{
Long non-coding RNA H19 promotes colorectal cancer metastasis via binding to hnRNPA2B1
}

Yuhui Zhang ${ }^{1 \dagger}$, Weibin Huang ${ }^{1 \dagger}$, Yujie Yuan ${ }^{1 \dagger}$, Jin $\mathrm{Li}^{2}$, Jing Wu${ }^{2}$, Jie Yu${ }^{1}$, Yulong $\mathrm{He}^{1,2^{*}}$, Zhewei Wei ${ }^{1^{*}}$ and Changhua Zhang ${ }^{2^{*}}$

\begin{abstract}
Background: Long non-coding RNA H19 was demonstrated to be significantly correlated with tumor metastasis. However, the specific functions of $\mathrm{H} 19$ in colorectal cancer (CRC) metastasis and the underlying mechanism are still largely unclear.

Methods: Use public database to screen the potential IncRNA crucial for metastasis in colorectal cancer. The expression of $\mathrm{H} 19$ in clinical CRC specimens was detected by qRT-PCR. The effect of H19 on the metastasis of CRC cells was investigated by transwell, wound healing assays, CCK-8 assays and animal studies. The potential proteins binding to H19 were identified by LC-MS and verified by RNA immunoprecipitation (RIP). The expression of indicated RNA and proteins were measured by qRT-PCR or western blot.

Results: We found the expression of IncRNA H19 was significantly upregulated in primary tumor and metastatic tissues, correlated with poor prognosis in CRC. Ectopic H19 expression promoted the metastasis of colorectal cancer cells in vitro and in vivo, and induced epithelial-to-mesenchymal transition (EMT). Mechanistically, H19 directly bound to hnRNPA2B1. Knockdown of hnRNPA2B1 attenuated the H19-induce migration and invasion in CRC cells. Furthermore, $\mathrm{H} 19$ stabilized and upregulated the expression of Raf-1 by facilitated the interaction between hnRNPA2B1 and Raf-1 mRNA, resulting in activation of Raf-ERK signaling.

Conclusions: Our findings demonstrate the role of H19/hnRNPA2B1/EMT axis in regulation CRC metastasis, suggested $\mathrm{H} 19$ could be a potential biomarker to predict prognosis as well as a therapeutic strategy for CRC.
\end{abstract}

Keywords: Colorectal cancer, Metastasis, H19, hnRNPA2B1, EMT

\section{Background}

Colorectal cancer (CRC) is the third most prevalent malignancies, accounts for 881,000 deaths around the world in 2018 [1]. Metastasis is common in CRC, which is the

\footnotetext{
*Correspondence: heyulong@mail.sysu.edu.cn; denisewei@126.com; zhchangh@mail.sysu.edu.cn

Yuhui Zhang, Weibin Huang and Yujie Yuan contributed equal to this work. 'Department of Gastrointestinal Surgery, the First Affiliated Hospital of Sun Yat-sen University, 58 Zhongshan 2nd Road, Guangzhou 510080,

Guangdong, China

${ }^{2}$ Center for Digestive Disease, the Seventh Affiliated Hospital of Sun Yat-sen University, 628 Zhenyuan Road, Shenzhen 518000, Guangdong, China
}

major cause for CRC associated deaths [2]. The 5-year survival rate for patients with unresectable metastases was under $10 \%$ in CRC, while for stage I disease was 90\% [3]. Therefore, to understand the molecular mechanisms driving metastasis and improve treatments strategy for metastasis are of urgent need in CRC.

Tumor metastasis is a multi-step process comprising of a wide variety of molecular events [4]. Increasing long non-coding RNAs (lncRNA) have recently emerged as promising mechanism for metastases in various kinds of cancers [5]. LncRNA comprise of a series of transcripts

(c) The Author(s). 2020, corrected publication 2021. Open Access This article is licensed under a Creative Commons Attribution 4.0 International License, which permits use, sharing, adaptation, distribution and reproduction in any medium or format, as long as you give appropriate credit to the original author(s) and the source, provide a link to the Creative Commons licence, and indicate if changes were made. The images or other third party material in this article are included in the article's Creative Commons licence, unless indicated otherwise in a credit line to the material. If material is not included in the article's Creative Commons licence and your intended use is not permitted by statutory regulation or exceeds the permitted use, you will need to obtain permission directly from the copyright holder. To view a copy of this licence, visit http://creativecommons.org/ licenses/by/4.0/. The Creative Commons Public Domain Dedication waiver (http://creativecommons.org/publicdomain/zero/1. 0/) applies to the data made available in this article, unless otherwise stated in a credit line to the data. 
more than 200 nt in length and occupy limited capacity to translate into proteins [6]. Recent findings have revealed that almost $98 \%$ of human transcriptome are non-coding RNAs [7], suggesting lncRNAs may involve in a wide range of pathophysiological processes $[8,9]$. Although several lncRNAs have been proved to be of great importance in the dysregulation of proliferation, apoptosis, migration, invasion and chemoresistance for CRC [10-13], the role of most other IncRNAs in colorectal cancer are rarely studied. Therefore, to identify potential lncRNAs involving metastases in CRC is of great need. By analyzing the public database, H19 was one of most overexpressed lncRNAs in primary tumor and metastatic tissues compared with adjacent normal tissues in CRC. Aberrant expression of H19 has been demonstrated in various kinds of malignancies including lung cancer, gastric cancer and pancreatic cancer [1416]. Furthermore, Zhou et al. reported that H19 lead to epithelial-to-mesenchymal transition (EMT), a pivotal step in cancer metastasis [17], by acting as miRNA sponges to inhibit the functions of related miRNA [18]. During EMT, epithelial cells acquire mesenchymal features, beneficial for migration and invasion of cancer cells, and eventually promotes infiltration and metastasis [19]. Recent studies have revealed lncRNAs trigger EMT and subsequently lead to tumor metastasis [20, 21]. Nevertheless, the exact effect of H19 in CRC and the mechanism in regulating metastasis is remain largely unknown.

In the current study, we identified lncRNA H19 as one of the lncRNAs increased most substantially in primary colorectal cancer tissues, which was further upregulated in metastatic tissues by analyzing public dataset and confirmed with clinical specimens. Functional analyses demonstrated that $\mathrm{H} 19$ promotes the metastases of colorectal cancer cells both in vitro and in vivo. Furthermore, mechanistic studies demonstrated that by directly binding to heterogeneous nuclear ribonucleoprotein A2B1 (hnRNPA2B1), H19 activate Raf-ERK signaling and induce EMT, resulting in the metastases of CRC cells. Collectively, we suggested that H19 could be a potential prognosis biomarker and therapeutic target for colorectal cancer.

\section{Materials and methods}

\section{Patient and clinical samples}

A total of 60 pairs of colorectal cancer samples and corresponding adjacent non-tumor colonic epithelium tissues, as well as 11 liver metastasis specimens were acquired from patients at The First Affiliated Hospital, Sun Yat-sen University (Guangzhou, China). Specimens were frozen in liquid nitrogen immediately after resection and stored at $-80^{\circ} \mathrm{C}$. These tissue samples were examined by pathologists. All patients provided written informed consent and the Ethics Committee of The First Affiliated Hospital, Sun Yat-sen University approved the current study.

\section{Cell lines and culture conditions}

Human CRC cell HCT116, SW480 and DLD1 were purchased from Shanghai Institute of Cell Biology, Chinese Academy of Sciences (Shanghai, China). HCT116 and SW480 were cultured in Dulbecco's Modified Eagle's Medium (Gibco, Logan, UT, USA), DLD1 were maintained in RPMI 1640 Medium (Gibco) in a thermostatic incubator at $37^{\circ} \mathrm{C}$ with $5 \% \mathrm{CO}_{2}$. Medium were added with $10 \%$ fetal bovine serum (Gibco) for regular culture.

\section{Transfection and stable cell lines construction}

Cell transfection with small interfering RNA (siRNA) was performed using Lipofectamine 3000 reagent (Invitrogen, Carlsbad, CA, USA). Two independent siRNAs for hnRNPA2B1 and negative control (RiboBio, Guangzhou, China) were introduced into cells according to the manufacturer's instructions. For construction of stable H19 overexpression and control cell lines, full length H19 (NR2196.2) and empty lentiviral vector control were synthesized and cloned into a lentiviral vector pEZ-Lv201 (Genecopeia, Guangzhou, China) named pEZ-Lv201-H19 and pEZ-Lv201-Vector respectively, and transfected into HCT116 and SW480 cells. After $72 \mathrm{~h}, 1 \mu \mathrm{g} / \mathrm{ml}$ puromycin was add for 4 weeks to establish stable cell lines. To construct stable H19 knockdown cell lines, two pairs of cDNA oligonucleotides suppressing H19 were cloned into the lentiviral vector psi-LVRU6GP (Genecopeia), called shH19-1 and sh-H19-2. A scrambled shRNA was employed as negative control and named sh-NC. After transfected sh-H19-1, sh-H19-2 and sh-NC into HCT116 and DLD1 cells lines, cells were selected with $1 \mu \mathrm{g} / \mathrm{ml}$ puromycin for 4 weeks to construct stable cell lines. For construction of overexpressed Raf-1 cell lines, full length Raf-1(NM2880.3) was cloned into pEZ-M02 vector and a vector with eGFP was used as control (Genecopeia). Plasmid was transfected by using Lipofectamine 3000 reagent (Invitrogen). The siRNA and shRNA sequences are listed in Supplementary Table S1 and S2.

RNA isolation and quantitative real-time PCR (qRT-PCR) Total RNA was isolated using RNAiso Plus (Takara, Dalian, China) according to the manufacturer's instruction. Separation of nuclear and cytoplasm RNA were by using PARIS ${ }^{\text {mix }}$ Kit (Life Technologies, Gaithersburg, MD, USA) following the manufacturer's instruction. Next, reverse transcription was carried out using the PrimeScript $^{\text {ma }}$ RT Master Mix (Takara) following the manufacturer's instruction. Quantitative real-time PCR (qRT-PCR) assays were performed using TB Green ${ }^{\circ}$ Premix Ex Taq ${ }^{\text {Th }}$ II (Takara) by ABI 7900HT Fast RealTime 
PCR System (Applied Biosystems, Foster City, CA, USA) according to the manufacturers' protocols. GAPDH was used as an endogenous reference for indicated genes to normalize. To detect RNA in different cellular fractionation, the expression of $\beta$-actin was used as cytoplasmic control and U6 as nuclear control. Sequences of primers used for qRT-PCR in this study were shown in Supplementary Table S3.

\section{Western blot analysis}

Total proteins were isolated by using RIPA supplemented with protease and phosphatase inhibitor reagents (Thermo-Fisher Scientific, Waltham, MA, USA). Nuclear and cytoplasm proteins were isolated by PARIS ${ }^{\mathrm{mi}}$ Kit (Life) according to the manufacturer's instruction. Protein was separated using sodium dodecyl sulfatepolyacrylamide gel electrophoresis (SDS-PAGE). After transferred proteins to PVDF membranes (Merck Millipore, Billerica, MA, USA), membranes were blocked in $5 \%$ skim milk for $1 \mathrm{~h}$ at room temperature followed by incubated with primary antibodies overnight at $4{ }^{\circ} \mathrm{C}$. After three washes with TBST, PVDF membranes were incubated with HRP-conjugated goat anti-mouse (\#7076, Cell signaling Technology, Danvers, MA, USA) or antirabbit (\#7074, CST) secondary antibodies for $1 \mathrm{~h}$ at room temperature. Anti-GAPDH antibody (\#5174), antiTubulin antibody (\#2146), anti-Lamin B1 antibody (\#13435), anti-Snail antibody (\#3879), anti-E-cadherin antibody (\#3195), anti-N-cadherin antibody (\#13116), anti-ERK1/2 antibody (\#9102), anti-Phospho-ERK1/2 antibody (\#9101), anti-Raf-1 antibody (\#9422) were from Cell Signaling Technology; anti-hnRNPA2B1 antibody (ab6102) was from Abcam (Cambridge, MA, USA).

\section{Cell migration and invasion assays}

The capability of migration and invasion in indicated cancer cells were evaluated by transwell assays. Briefly, for invasion assay, $5 \times 10^{\wedge} 4$ cells were suspended in serum-free medium and seed into the upper chamber (8- $\mu \mathrm{m}$ pore size, BD Biosciences, San Jose, CA, USA)) with diluted Matrigel (Corning, NY, USA). Medium supplemented plus $20 \%$ fetal bovine serum was added to the lower chambers. After incubation for $48 \mathrm{~h}$, wiped off cells remained in the upper chamber. Then fixed cells with $4 \%$ paraformaldehyde followed by stained with $0.1 \%$ crystal violet. The cells migrated or invaded to lower chamber were counted and imaged in three different fields with a microscope.

\section{Pharmaceuticals}

The ERK1/2 inhibitor SCH772984 was purchased from Selleck Chemicals (S7101, Houston, TX, USA). Exponential growing cells seeded in 6-well plates were treated

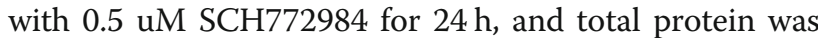
isolated as described above.

\section{RNA pull-down assay}

Full-length $\mathrm{H} 19$ and its antisense RNA were transcribed in vitro using TranscriptAid T7 High Yield Transcription Kit (\#K0441, Thermo), treated with RNase-free DNase I (Takara), and purified with GeneJET RNA Purification Kit (\#K0731, Thermo) according to the manufacturer's instruction. Then, RNAs were labeled with desthiobiotinylate using PierceTM RNA 3'end Desthiobiotinylation Kit (\#20163, Thermo). RNA pull-down assay was performed using PierceTM Magnetic RNAprotein Pull Down Kit (\#20164, Thermo) according to the manufacturer's instruction. Finally, the RNA-binding proteins were analyzed by liquid chromatography-mass spectrometry (LC-MS) (Triple TOF 6600 LC-MS, AB SCIEX, USA) or followed by western blot.

\section{RNA immunoprecipitation (RIP)}

EZ-Magna RIP RNA Binding Protein Immunoprecipitation Kit (17-700, Millipore) was used to perform RIP assays following the protocol. Anti-hnRNPA2B1 (ab6102, Abcam) antibody and normal mouse Ig (GCS200621, Millipore) were used to immunoprecipitated with target RNA or as a negative control. Finally, RNA was subjected to qRT-PCR analysis as described above to detect the enrichment between indicated RNA binding to hnRNPA2B1.

\section{Immunofluorescence (IF) assay}

Cancer cells were seeded onto sterile slides into 24-well culture plates. Then, fixed cells with $4 \%$ paraformaldehyde for $20 \mathrm{~min}$ when reached a confluence of $80 \%$. Following permeabilized membranes with $0.1 \%$ Triton X-100 for 10 min, blocked antigens with $10 \%$ goat serum for $30 \mathrm{~min}$ in room temperature. Cells were then incubated with anti-hnRNPA2B1 (ab6102, Abcam) at a 1:100 dilution overnight at $4{ }^{\circ} \mathrm{C}$, followed by further incubation at room temperature for $1 \mathrm{~h}$ with AlexaFluor Plus 555 goat anti-mouse IgG secondary antibody (A32727, Thermo) and then labeled DNA with DAPI for $10 \mathrm{~min}$.

\section{RNA stability}

Exponential growing cells were treated with $2.5 \mu \mathrm{g} / \mathrm{ml}$ actinomycin D (Act-D, \#A9415, Sigma-Aldrich, St. Louis, MO, USA) and incubated at the indicated times. Then RNA was isolated as described above for qRT-PCR. GAPDH was used for normalization.

\section{Wound healing assay}

Cancer cells were seeded into six-well culture plates and cultured until reach $80-90 \%$ confluence. Then scratched cells off in a straight line by sterile $100-\mu l$ pipette tips and replaced media with serum-free media. Images were 
recorded by using microscope $48 \mathrm{~h}$ after the initial scratches and calculated the distance of wound healing compared to $0 \mathrm{~h}$.

\section{Cell counting Kit-8 (CCK-8) assay}

Cell proliferation was detected by CCK-8 reagent (CK04, Dojindo, Japan). 1000 indicated cells were inoculated into 96-well plates with complete medium for 0 (when cells were adhered), 24.48 and $72 \mathrm{~h}$. Replaced medium with medium added $10 \%$ CCK- 8 and incubated for $2 \mathrm{~h}$ at $37^{\circ} \mathrm{C}$. Proliferation of cells were measured by using a microplate reader (Multiskan FC, Thermo) at a $450 \mathrm{~nm}$ wavelength.

\section{Animal study}

To establish lung metastasis model, female BALB/c nude mice were purchased from Laboratory Animal Center of Sun Yat-sen University (Guangzhou, China). Mice were bred and maintained in a pathogen-free facility until the age of 6 -week. $1 \times 10^{\wedge} 6 \mathrm{H} 19$ overexpressed or control cells were suspended in $100 \mu \mathrm{L}$ PBS and injected into the tail vein. Experiments were terminated and mice were sacrificed 6 weeks after injection. The lungs from the two groups were anatomized, fixed in formalin, paraffin embedded then analyzed with hematoxylin and eosin (HE) staining to confirm metastatic foci. The handling of mice was strictly under the approval of committee on the Ethics of Animal Experiments of The First Affiliated Hospital, Sun Yat-sen University.

\section{Statistical analysis}

Statistical analyses were performed using SPSS Statistics software version 18.0 software (IBM SPSS Statistics Company, Armonk, NY, USA). All data are presented as the mean $\pm \mathrm{SD}$. Appropriate statistical methods including Student's t-test, Wilcoxon signed-rank test, MannWhitney test, Pearson chi-square test were used to calculate differences between groups. Spearman's correlation analysis was assessed correlation between genes. The Kaplan-Meier method with the log-rank test was used to calculate survival rate between groups. $P$-values $<0.05$ was considered to be statistically significant.

\section{Results}

$\mathrm{H} 19$ is upregulated in colorectal cancer and associated with poor survival outcomes

To screen the potential lncRNA crucial for metastasis in colorectal cancer, we analyzed the public RNA-seq dataset including 18 colorectal cancer patients with matched normal colonic epithelium, primary lesion and liver metastases tissues (GSE50760) [22]. H19 was one of the most substantially changed lncRNA between normal colonic epithelium and paired CRC tissues. Further analysis of expression of lncRNA between primary CRCs and liver metastasis tissues demonstrated that H19 is also overexpressed compared with that in primary tumors (Fig. 1a and b). To validate the expression pattern of $\mathrm{H} 19$, we analyzed 60 primary CRC specimens and corresponding adjacent non-tumor tissues from the tissue bank of the first affiliated hospital of Sun Yat-sen university by qRT-PCR. Our data suggested that H19 is also upregulated in primary tumors compared with paired colonic epithelium tissues (Fig. 1c). To confirmed the association between $\mathrm{H} 19$ and clinicopathologic features of CRC, these clinical samples were divided into two group according to the median expression of $\mathrm{H} 19$ in primary lesions. High H19 expression was associated with more lymph node metastasis and distant metastasis (Table 1). The expression of H19 in samples with $(n=$ $11)$ or without $(n=49)$ metastasis was measured to elucidate the relationship between H19 and distant metastasis. And H19 was remarkably increased in primary lesions with metastasis compared to those without metastasis (Fig. 1d). Furthermore, we collected and evaluated the expression of $\mathrm{H} 19$ in the matched liver metastatic tissues. The expression of H19 in liver metastases was higher than that in matched primary tumors (Fig. 1e). The Kaplan-Meier analysis and log-rank test suggested that CRC patients with high H19 expression was corelated with decreased overall survival (Fig. 1f). Taken together, these data concluded that H19 overexpression was correlated with CRC distance metastasis and poor prognosis.

\section{H19 promotes CRC migration, invasion and EMT in vitro and in vivo}

To investigate the function of $\mathrm{H} 19$ in CRC metastasis, we transfected LV-H19 and control LV-vector to construct H19 stably overexpression HCT116 and SW480 cells (Fig. S1 and S2a). Meanwhile, two independent shRNAs against H19 were transfected into HCT116 and DLD1 cells to establish H19 stably knockdown cells (Fig. S2b). Transwell assays suggested that H19 overexpression promote the migration and invasion of HCT116 and SW480 cells (Fig. 2a and b), whereas knockdown of H19 inhibited migration and invasion of HCT116 and DLD1 cells (Fig. 2c and d). The wound healing assay also confirmed that H19 overexpression promoted cell migration and H19 depletion inhibited cell motility (Fig. S3a and S3b). To further investigate the role of H19 in metastases in vivo, stably overexpressed and control HCT116 cells were injected into BALB/c nude mice through the tail vein to establish lung metastasis model. Our results revealed that overexpression of H19 in HCT116 cells lead to more metastatic tumors in lung and larger tumor size compared to control group (Fig. $2 \mathrm{e}-\mathrm{g})$. In addition, CCK-8 analysis demonstrated upregulated or depleted H19 had no significant effect on cell 


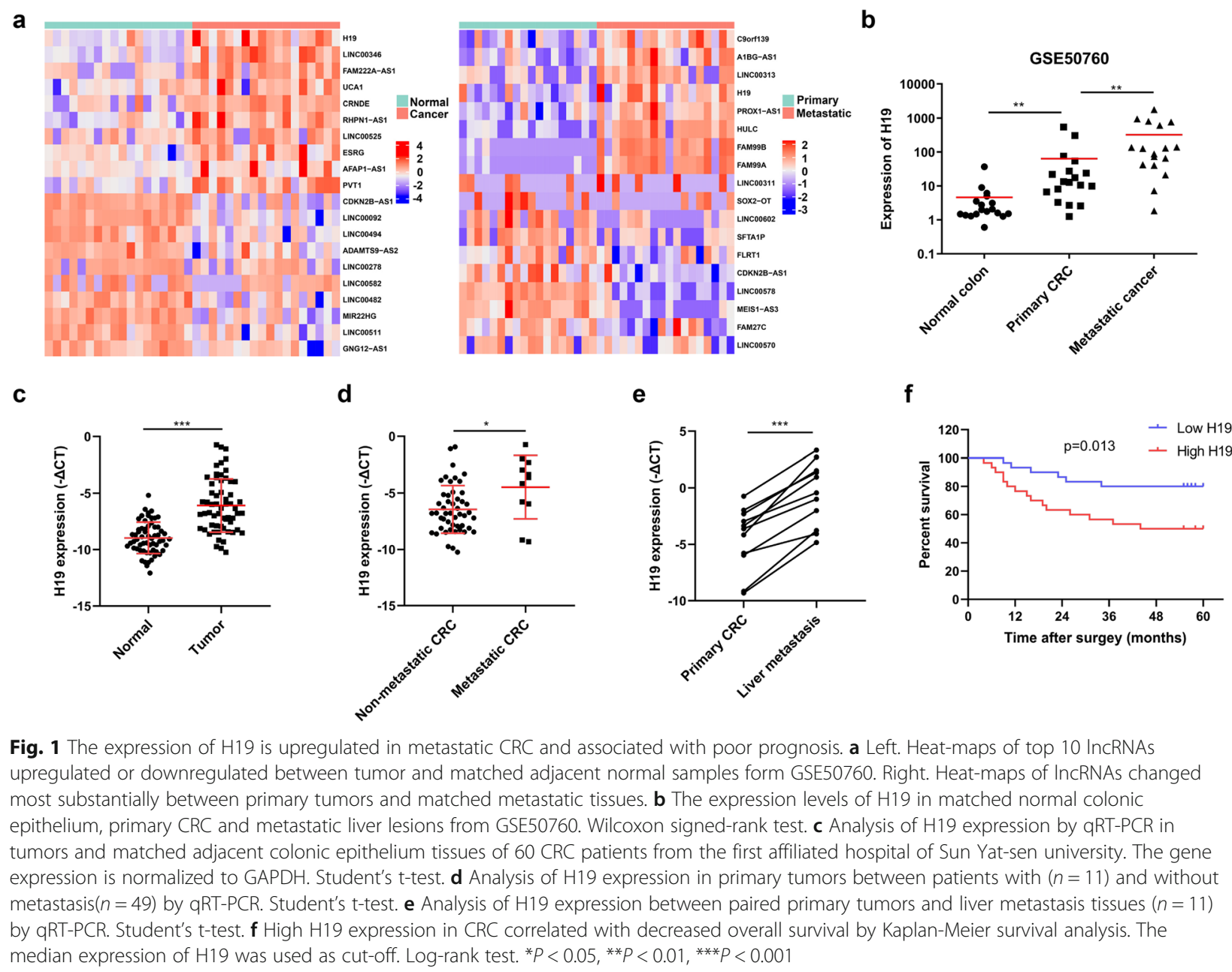

proliferation of CRC cell lines (Fig. S4a and S4b). These results suggested that $\mathrm{H} 19$ can contribute to the dissemination of CRC cells in vitro and in vivo.

To further investigate how $\mathrm{H} 19$ regulate metastasis in colorectal cancer, correlation analysis was performed to confirm the related genes of H19 in The Cancer Genome Atlas (TCGA) colorectal adenocarcinoma database. The result displayed that SNAI1 (Snail), a crucial EMT transcript factor, was one of the most relevant genes with H19 (Fig. 3a and S5), suggested H19 may involve in the progression of EMT in colorectal cancer. In addition, Gene Set Enrichment Analysis (GSEA) in gene expression profiles of colorectal cancer patients obtained from the TCGA database indicated that EMT pathway from the Molecular Signatures Database [23] and two published EMT gene signatures $[24,25]$ were significantly enriched in samples with high level of H19, demonstrated H19 is highly correlated with EMT signaling (Fig. $3 \mathrm{~b})$. To validated the association between H19 and EMT in colorectal cancer, we first confirmed the influence of H19 on the expression of EMT transcript factors in CRC cells because of their direct functions to induce EMT. RT-PCR data suggested that H19 overexpression increase the mRNA level of Snail but not Slug, Smuc, Zeb1, Zeb2, Twist1, Twist2 or E12/E47 in HCT116 and SW480 cells (Fig. 3c and S6a). Consistently, H19 depletion reduce the expression of Snail but not Slug, Smuc, Zeb1, Zeb2, Twist1, Twist2 or E12/E47 in HCT116 and DLD1 cells (Fig. 3d and S6b). Western blot result indicated H19 overexpression increased the expression of Snail, N-cadherin and inhibited E-cadherin expression (Fig. 3e), whereas H19 depletion downregulated Snail, $\mathrm{N}$-cadherin expression and upregulated the expression of E-cadherin (Fig. 3f). Hence, these results suggested that $\mathrm{H} 19$ promote EMT, migration, invasion and metastasis of CRC cells.

\section{H19 specifically binds to hnRNPA2B1}

Since lncRNA can implement their functions through binding to proteins [26, 27], RNA pull-down assays were performed followed by LC-MS to detect the target of H19 (Figs. 4a, S7 and Table S4). The result demonstrated that 
Table 1 Correlation between H19 expression and clinicopathologic features of CRC

\begin{tabular}{|c|c|c|c|c|}
\hline \multirow[t]{2}{*}{ Features } & \multirow{2}{*}{$\begin{array}{l}\mathrm{N} \text { of } \\
\text { cases }\end{array}$} & \multicolumn{2}{|l|}{$\mathrm{H} 19$} & \multirow[t]{2}{*}{$p$-value } \\
\hline & & Low & High & \\
\hline Total & 60 & 30 & 30 & \\
\hline Age (years) & & & & 0.795 \\
\hline$>65$ & 34 & 18 & 16 & \\
\hline$\leq 65$ & 26 & 12 & 14 & \\
\hline Gender & & & & 0.438 \\
\hline Male & 32 & 14 & 18 & \\
\hline Female & 28 & 16 & 12 & \\
\hline Tumor size $(\mathrm{cm})$ & & & & 0.119 \\
\hline$>3$ & 33 & 13 & 20 & \\
\hline$\leq 3$ & 27 & 17 & 10 & \\
\hline Depth of invasion & & & & 0.613 \\
\hline $\mathrm{T} 1$ & 3 & 1 & 2 & \\
\hline $\mathrm{T} 2$ & 7 & 4 & 3 & \\
\hline $\mathrm{T} 3$ & 30 & 17 & 13 & \\
\hline T4 & 20 & 8 & 12 & \\
\hline Lymph node metastasis & & & & 0.010 \\
\hline NO & 33 & 19 & 14 & \\
\hline N1 & 16 & 10 & 6 & \\
\hline N2 & 11 & 1 & 10 & \\
\hline Distant metastasis & & & & 0.042 \\
\hline Mo & 49 & 28 & 21 & \\
\hline M1 & 11 & 2 & 9 & \\
\hline AJCC stage & & & & 0.127 \\
\hline I & 8 & 4 & 4 & \\
\hline$\|$ & 25 & 15 & 10 & \\
\hline III & 16 & 9 & 7 & \\
\hline IV & 11 & 2 & 9 & \\
\hline
\end{tabular}

The median expression level of $\mathrm{H} 19$ was used as cut-off

$P$-value was acquired by Pearson chi-square tests

hnRNPA2B1 was one of the most abundant proteins interacting with $\mathrm{H} 19$, which has been reported to regulate EMT and metastasis in tumors [28]. Hence, hnRNPA2B1 were selected as candidates for subsequent mechanistic experiments. First, western blot followed RNA pull-down assays confirmed the capability of hnRNPA2B1 binding to H19 in HCT116 cells (Fig. 4b). Consistently, RNA immunoprecipitation assays suggested that the enrichment of $\mathrm{H} 19$ precipitated by antibodies against hnRNPA2B1 increased greatly compared with those by control IgG in HCT116 and DLD1 cells, which further validated the interactions between H19 and hnRNPA2B1 (Fig. 4c). To further investigate the role of hnRNPA2B1 in H19-regulated metastasis in colorectal cancer, we separated the nuclear fractionation and cytoplasm fractionation of HCT116 and SW480 cells to investigate the distribution of $\mathrm{H} 19$ in subcellular fraction. RT-
PCR demonstrated H19 distributes in cytoplasm as well as in nucleus (Fig. 4d), suggested H19 could implement its functions at the transcriptional or post-transcriptional level. Next, we tried to elucidate whether $\mathrm{H} 19$ can regulate the expression of hnRNPA2B1 through their interactions or not. Western blot result indicated H19 overexpression did not influence total protein level of hnRNPA2B1 in HCT116 or SW480 cells (Fig. 4e). It has been reported that some hnRNPs shuttle between the nucleus and the cytoplasm [29], and consequently facilitated its binding to the target RNA [30]. Thus, the distribution of hnRNPA2B1 in H19 overexpression and control colorectal cancer cells were compared. Our results demonstrated H19 overexpression enhance the enrichment of hnRNPA2B1 in the cytoplasm (Fig. 4f), while knockdown of H19 decrease cytoplasmic hnRNPA2B1 (Fig. 4g). Furthermore, immunofluorescence also confirmed H19 overexpression increase the protein level of hnRNPA2B1 in cytoplasm (Fig. 4h) and H19 depleted reduce the enrichment of hnRNPA2B1 in cytoplasm (Fig. S8). Taken together, these data suggested that H19 specifically binds to hnRNPA2B1 and promote its translocation from nucleus to cytoplasm.

\section{H19 regulates EMT through hnRNPA2B1 dependent ERK pathway}

Next the effect of hnRNPA2B1 in metastases were explored to test whether it is a downstream mechanism of H19. Knockdown of hnRNPA2B1 inhibited the migration and invasion of HCT116 and SW480 cells (Fig. 5a and b) as well as inhibited EMT (Fig. 5c), suggested a positive role, similar as H19, in regulating EMT. Next, we investigate whether $\mathrm{H} 19$ promote EMT and metastasis depending on hnRNPA2B1 in CRC. Silencing of hnRNPA2B1 in HCT116-H19 or SW480-H19 cells attenuated H19-induced migration and invasion (Fig. 5d and e). These results suggested that hnRNPA2B1 contribute to the invasiveness of colorectal cancer cells induced by H19. Emerging evidence demonstrated that hnRNPA2B1 promotes tumor metastasis through extracellular regulated protein kinases (ERK) pathway [31]. We therefore investigated the functions of H19 and hnRNPA2B1 in ERK pathway. Western blot analysis demonstrated that H19 overexpression elevate the phosphorylation of ERK (Fig. 5f), while H19 knockdown lead to decreased phosphorylation of ERK (Fig. 5g). In addition, SCH772984, an ERK pathway inhibitor, attenuated the upregulation of Snail in HCT116-H19 and SW480-H19 cells (Fig. 5h). These results indicated that H19 regulate the expression of Snail through the activation of ERK signaling. Furthermore, knockdown of hnRNPA2B1 reversed the phosphorylation of ERK and upregulation of Snail in colorectal cancer cells with stable H19 overexpression (Fig. 5i). Collectively, our results demonstrated that $\mathrm{H} 19$ overexpression can lead to 


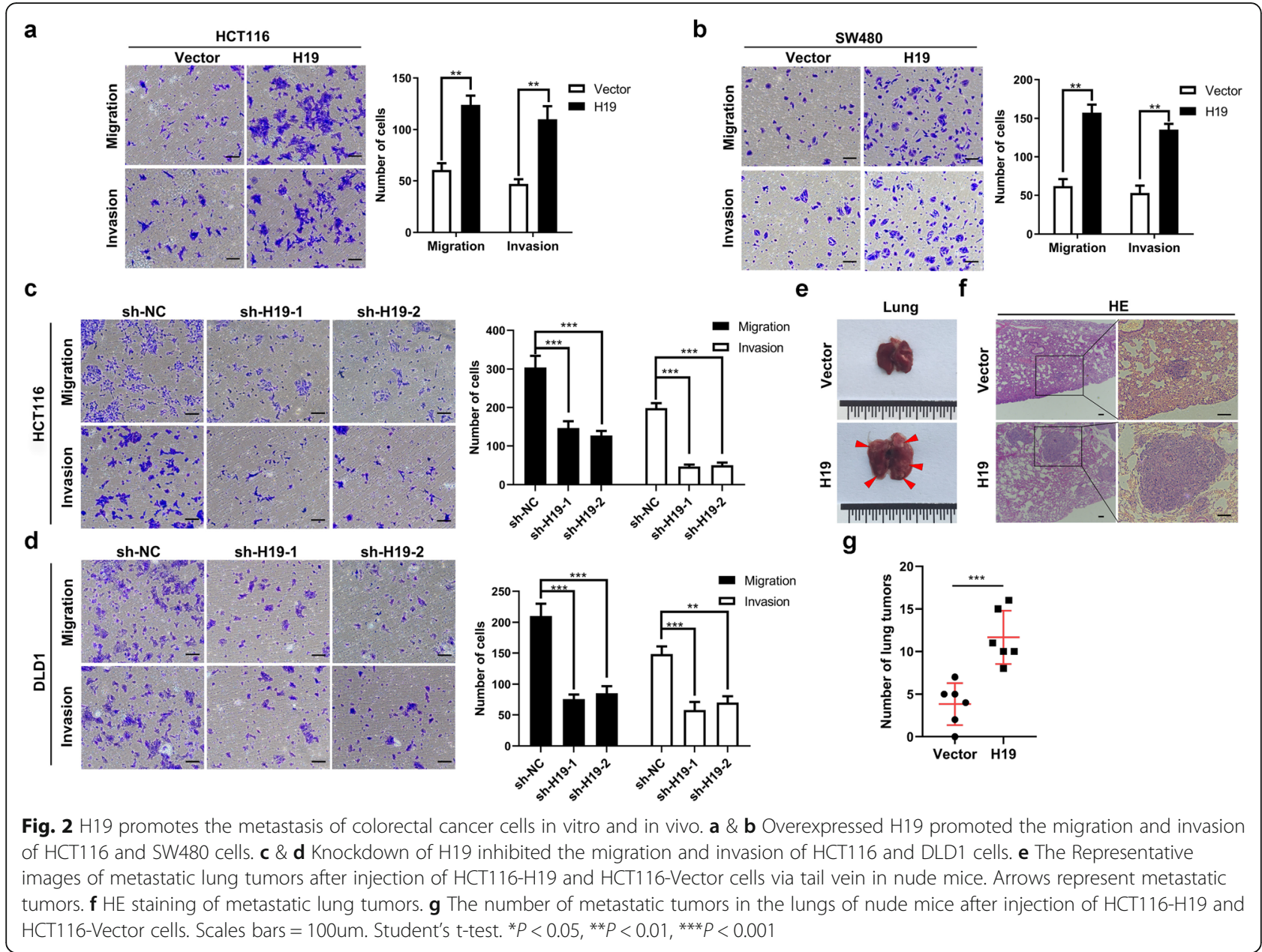

activation of ERK signaling through hnRNPA2B1, and eventually induced EMT and metastasis in CRC.

\section{H19 actives ERK signaling by upregulating Raf-1 expression}

We next sought to determine the underlying mechanism how H19 activate ERK signaling through hnRNPA2B1. It has been reported that hnRNPA2B1 regulates the expression and splicing of A-Raf [32], a member of Raf kinase family, which are main activators of ERK signaling [33]. Therefor we explored the function of H19 in regulating the expression of Raf kinase family. Knockdown hnRNPA2B1with siRNA reduced the mRNA level of Raf1 (C-Raf) and A-Raf, but not B-Raf in HCT116 and SW480 cells (Fig. 6a), whereas the overexpression or silencing of $\mathrm{H} 19$ only altered the mRNA level of Raf-1(Fig. $6 \mathrm{~b}$ and c), suggested Raf-1 may play a critical role in H19mediated activation of ERK signaling. Furthermore, we found that overexpression of $\mathrm{H} 19$ upregulated the protein levels of Raf-1 in HCT116 and SW480 cells (Fig. 6d). Simultaneously, hnRNPA2B1 knockdown reduced expression of Raf-1 (Fig. 6e). These results indicated that H19 and
hnRNPA2B1 regulated expression of Raf-1 at RNA level. To further confirmed the association between H19, hnrnpA2B1 and Raf-1, we analyzed the expression of H19, hnrnpA2B1 and Raf-1 in the primary colorectal cancer tissues and demonstrated the expression of H19 is positive correlated with Raf-1 (Figs. 6f, S9a and S9b). The recuse experiment revealed that overexpressed Raf-1 in H19depleted HCT116 cells upregulated the migration, invasion (Fig. 6g) and EMT (Fig. 6h) of HCT116 cells. Because hnRNPA2B1 stabilizes a variety of its target RNA [34], we suppose H19 upregulates the expression of Raf-1 through the interaction between hnRNPA2B1 and Raf- 1 mRNA. To further validate this, RIP assays were performed, and indicated a possible binding between hnRNPA2B1 and Raf-1 mRNA in HCT116 and SW480 cells (Fig. 6i). Next, we investigated the influence of $\mathrm{H} 19$ on the interaction between hnRNPA2B1 and Raf-1. RIP assays followed by qRT-PCR suggested that the enrichment of Raf-1 precipitated by antibodies against hnRNPA2B1 in H19 stable overexpression cells were increased significantly compared to that in control cells, revealing H19 facilitates the binding between 
a

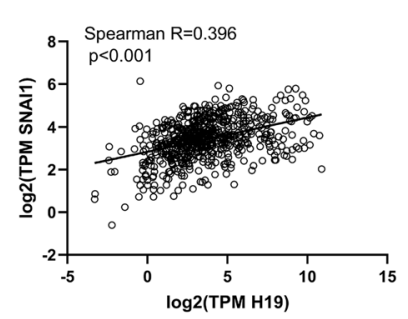

b

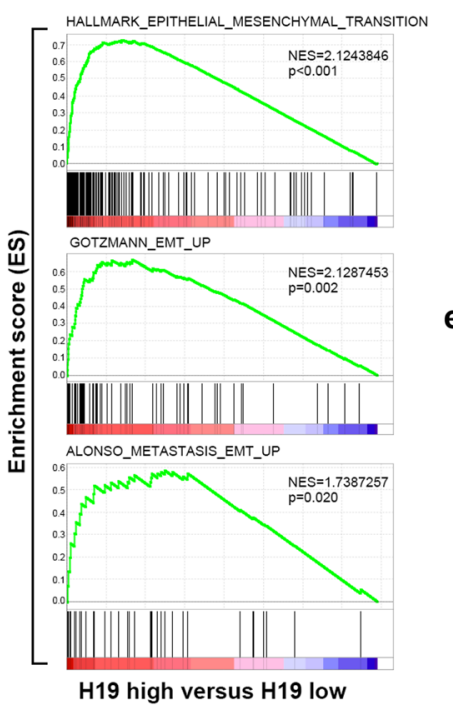

C

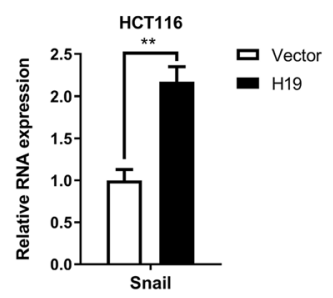

d

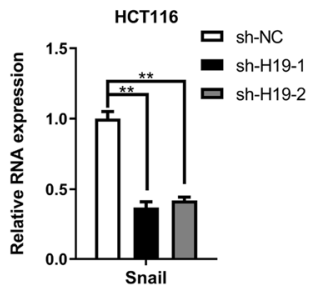

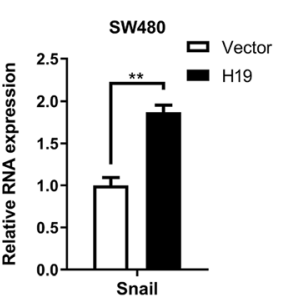

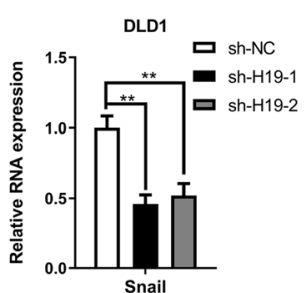

e

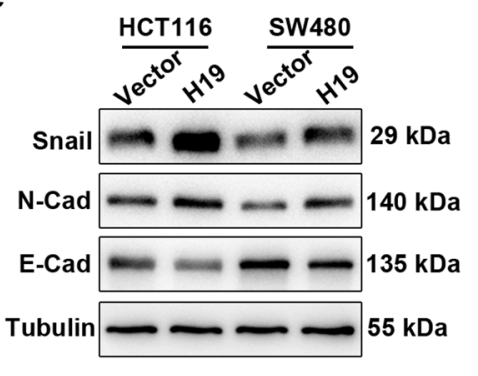

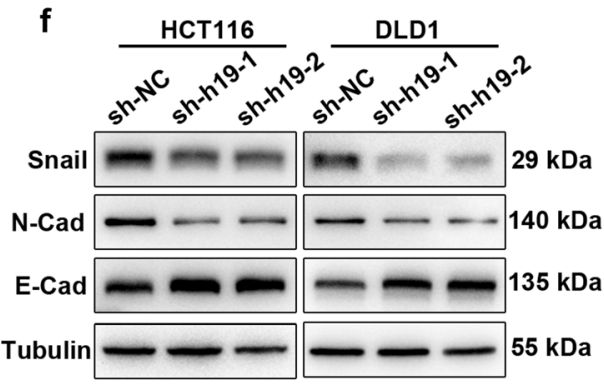

Fig. 3 Overexpression of H19 promotes EMT in colorectal cancer cells. a Correlation analysis of H19 and Snail expression in TCGA database. b GSEA of EMT gene signatures in colorectal cancer samples with high H19 expression versus those with low H19 expression in TCGA database. The median expression of H19 was used as cut-off. c Effect of forced expression of H19 on the mRNA level of Snail in HCT116 and SW480 cells were measured by qRT-PCR. $\mathbf{d}$ Effect of H19 knockdown on the mRNA level of Snail in HCT116 or DLD1 H19 cells were quantified by qRT-PCR. e Western blot analysis of EMT markers by ectopic expression of H19 in HCT116 and SW480 cells. f Western blot analysis of EMT markers in H19 knockdown or control cells. Student's t-test. ${ }^{*} P<0.05,{ }^{* *} P<0.01,{ }^{* *} P<0.001$

hnRNPA2B1 and Raf-1 (Fig. 6j). Consistently, H19 knockdown decreased the binding between hnRNPA2B1 and Raf-1 (Fig. S10), suggested the binding between hnRNPA2B1 and Raf-1 mRNA is H19 dependent. Furthermore, by treating cancer cells with Act-D to terminate transcription, our results demonstrated that silencing of hnRNPA2B1 significantly decrease the stability of Raf-1 in HCT116 and SW480 cells (Fig. 6k). Moreover, overexpression of H19 stabilized Raf-1 mRNA (Fig. 6l) while knockdown hnRNPA2B1 in HCT116-H19 and SW480-H19 attenuated the effect of $\mathrm{H} 19$ on the stability of Raf-1 (Fig. $6 \mathrm{~m})$, indicated $\mathrm{H} 19$ regulated Raf-1 expression via hnRNPA2B1 at post-transcript level. All together, these results suggested $\mathrm{H} 19$ enhanced the stability of Raf-1 mRNA via hnRNPA2B1, subsequently activated Raf-ERK signaling.

\section{Discussion}

Metastasis causes most cancer-related deaths in patients with colorectal cancer [2]. However, the critical molecules regulating tumor metastasis are still largely unknown. Among the complex process of metastasis development, long non-coding RNAs were identified to play important roles in regulating cancers metastasis [21]. In the present study, we demonstrate H19 promotes the migration, invasion and metastasis of colorectal cancer cells in vitro and in vivo. By binding to hnRNPA2B1, H19 leads to EMT via Raf-ERK dependent signaling, and finally promotes the dissemination of CRC.

LncRNA has been reported to exert crucial influence on the development of cancers [35]. Regarding the metastasis of CRC, few IncRNA have been functionally elucidated. To identified lncRNA related to metastasis in $\mathrm{CRC}$, the expression profile of CRC between primary tumors and metastases in public database were analyzed. H19 was supposed to be one of the top overexpressed IncRNA both in primary tumor and metastatic tissues compared with adjacent normal tissues. Some studies have demonstrated that the overexpression of H19 is associated with increased risk for several malignancies [36, 


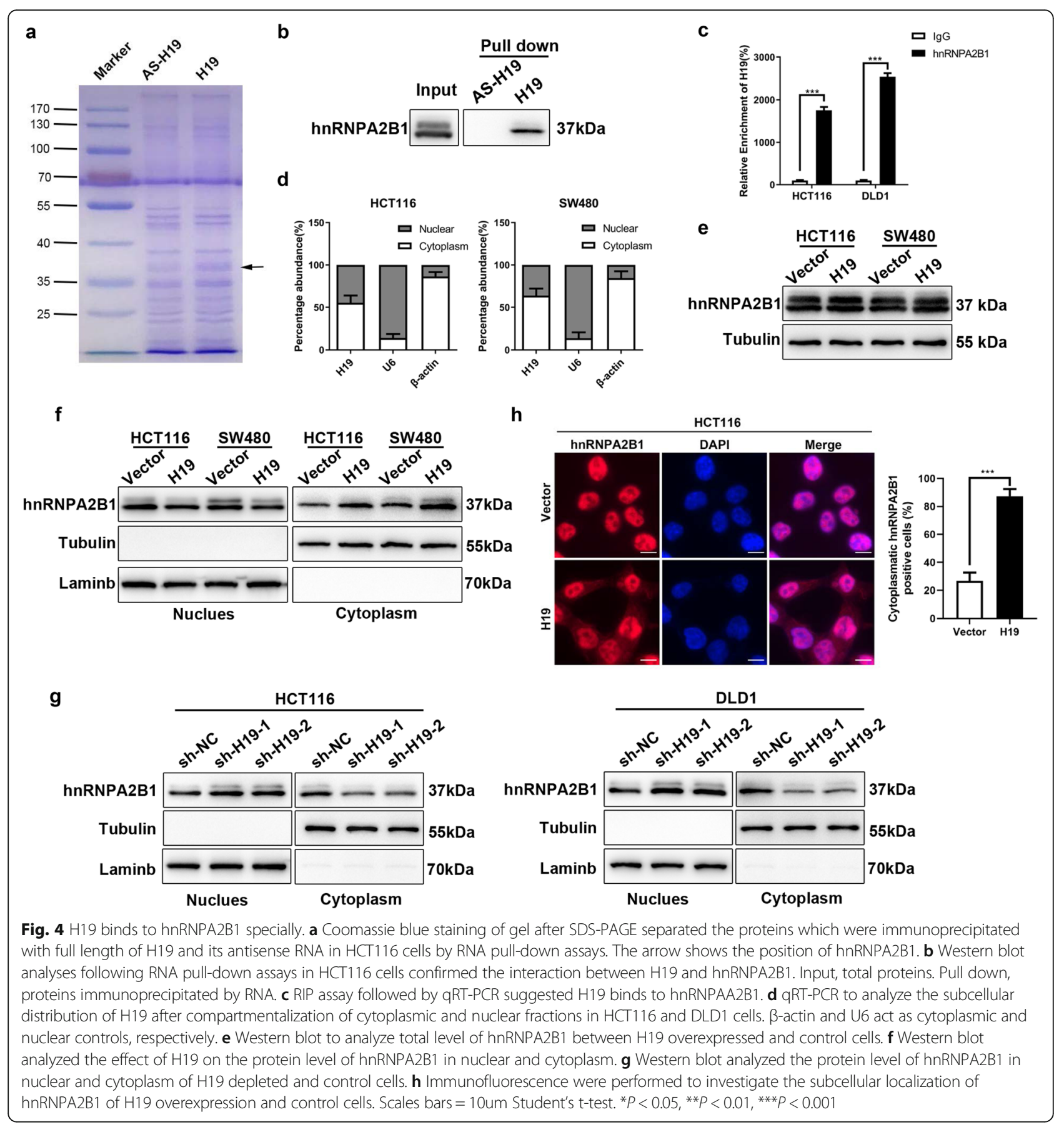

37]. Among that, $\mathrm{H} 19$ was reported to be potential prognostic biomarker to predict liver metastases in CRC patients [38], but the exact mechanism remained unclear. To further confirm the role of H19 in the regulation of CRC metastasis, we analyzed the expression pattern of H19 in clinical specimens. Our results revealed that H19 is upregulated in liver metastases and primary tumors compared with adjacent non-cancerous tissues. In addition, high $\mathrm{H} 19$ was associated with more positive lymph node and distance metastasis, and worse survival outcomes, suggesting $\mathrm{H} 19$ to be a potential predictor for CRC metastasis and prognosis.

Considering the increased expression and a potential pro-metastasis role of $\mathrm{H} 19$ in colorectal cancer, the effect of H19 on the invasiveness of CRC cells were evaluated in vitro. Overexpression of H19 markedly enhanced, whereas $\mathrm{H} 19$ silencing reduced the migration and invasion of HCT116 and SW480 cells. On the contrary, the CCK-8 assays found that $\mathrm{H} 19$ have no significant effect on the viability of HCT116 and SW480 cells because H19 may 


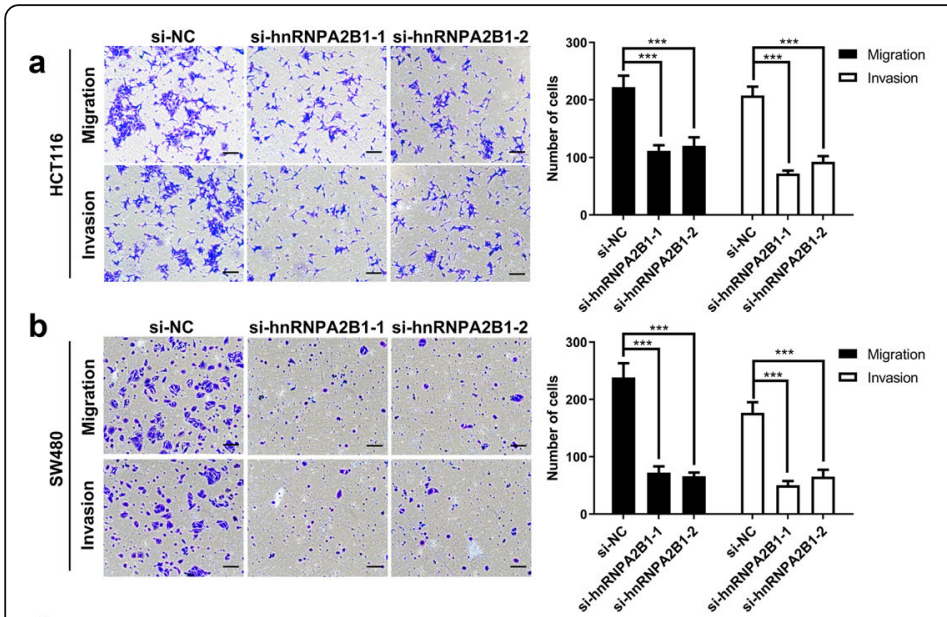

d
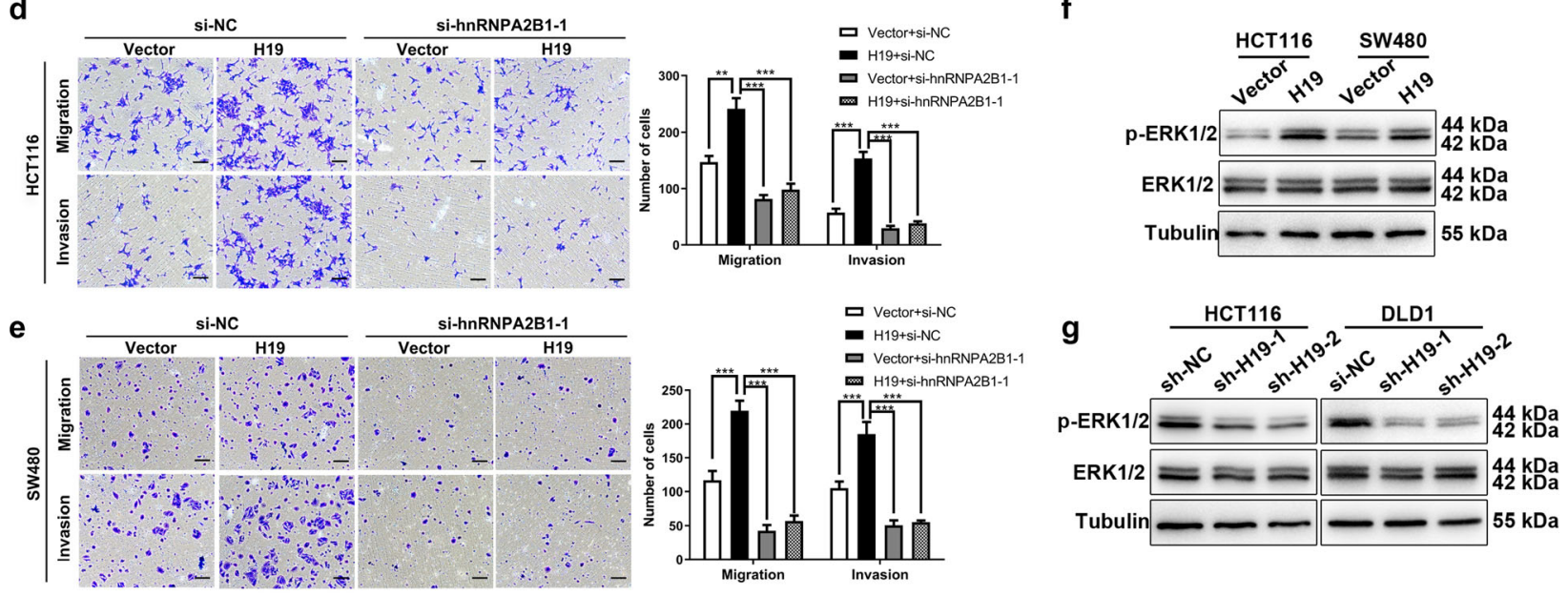

h

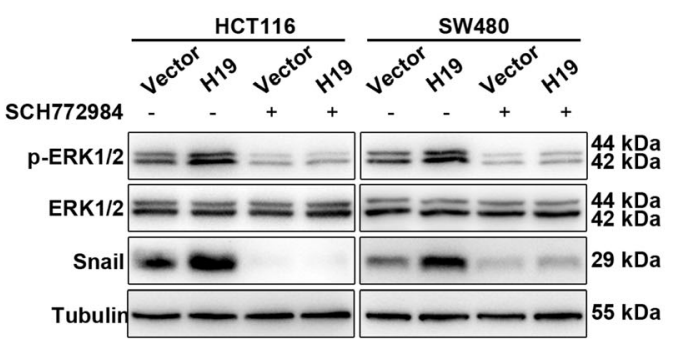

f
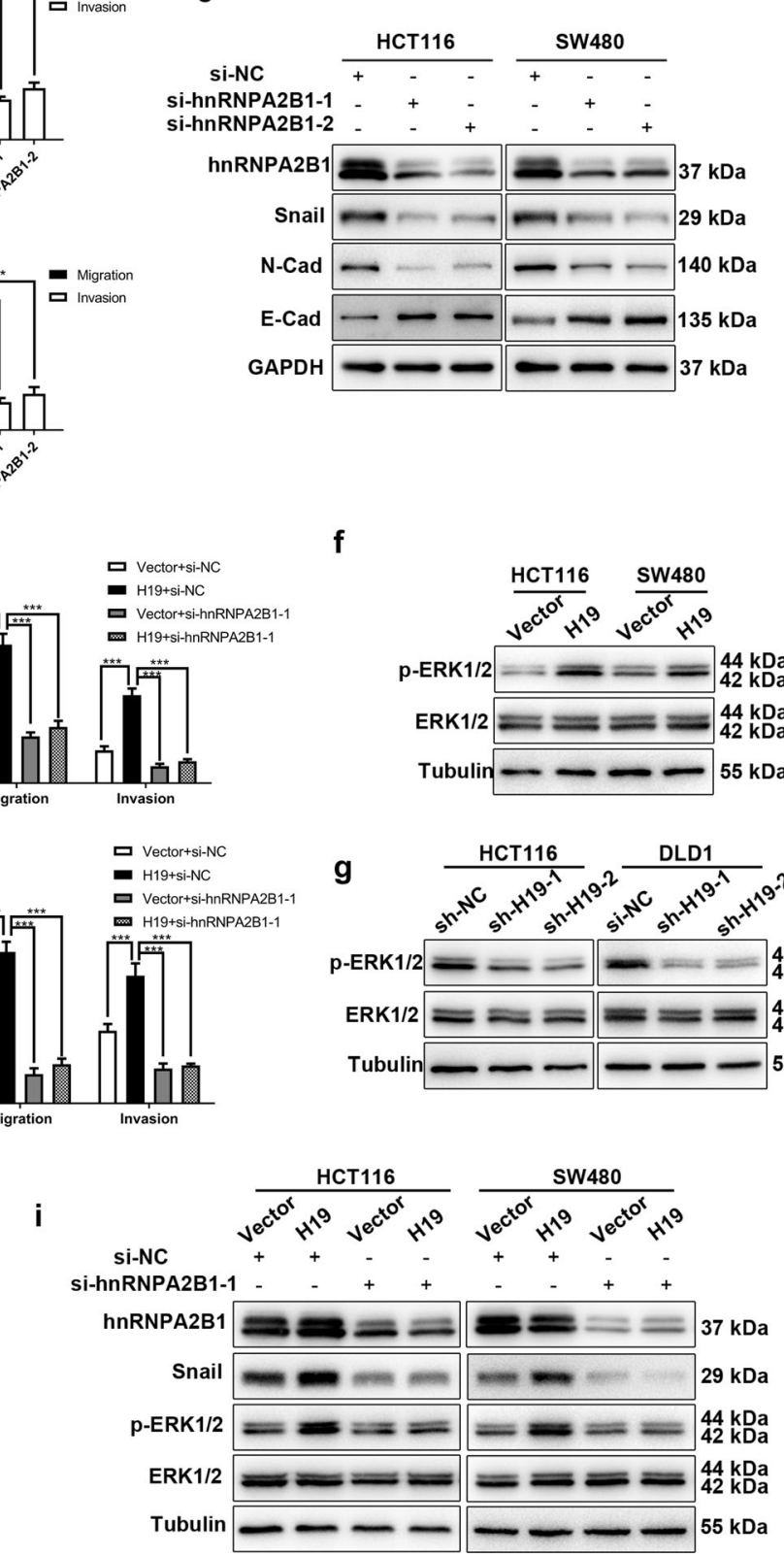

Fig. 5 H19 induced migration and invasion in colorectal cancer through hnRNPA2B1 a HnRNPA2B1 knockdown blocked the migration and invasion of HCT116 cells. b HnRNPA2B1 knockdown decreased the migration and invasion of SW480 cells. c Western blot analyses of EMT markers (Snail, E-cadherin and N-cadherin) after silencing of hnRNPA2B1in HCT116 and SW480 cells. d Knockdown of hnRNPA2B1 inhibited H19-induced migration and invasion in HCT116 cells. e Silencing of hnRNPA2B1 decreased H19-induced migration and invasion in SW480 cells. $\mathbf{f}$ Ectopic expression of $\mathrm{H} 19$ elevated the phosphorylation of ERK in colorectal cancer cells. $\mathbf{g}$ Western blot showed altered levels of p-ERK after H19 knockdown in HCT116 and DLD1 cells. $\mathbf{h}$ SCH772984 decreased the phosphorylation level of p-ERK, and the expression of Snail in HCT116-H19 and SW480-H19 cells. i HnRNPA2B1 knockdown reversed H19-induced p-ERK and Snail expression. Scales bars $=100$ um. Student's t-test. ${ }^{*} P<0.05,{ }^{* *} P<0.01,{ }^{* *} P<0.001$

mainly influence the cell motility but not viability of colorectal cancer, and further study on the influence of $\mathrm{H} 19$ on cell cycle should be carried out to ensure the underlying mechanism of H19. Further analysis in vivo demonstrated that overexpression of H19 leads to more metastases and larger tumor size in lung compared with control cells. Taken together, these results suggested that $\mathrm{H} 19$ promoted colorectal cancer metastases in vitro and in vivo, but exerted no influence on cell viability. 


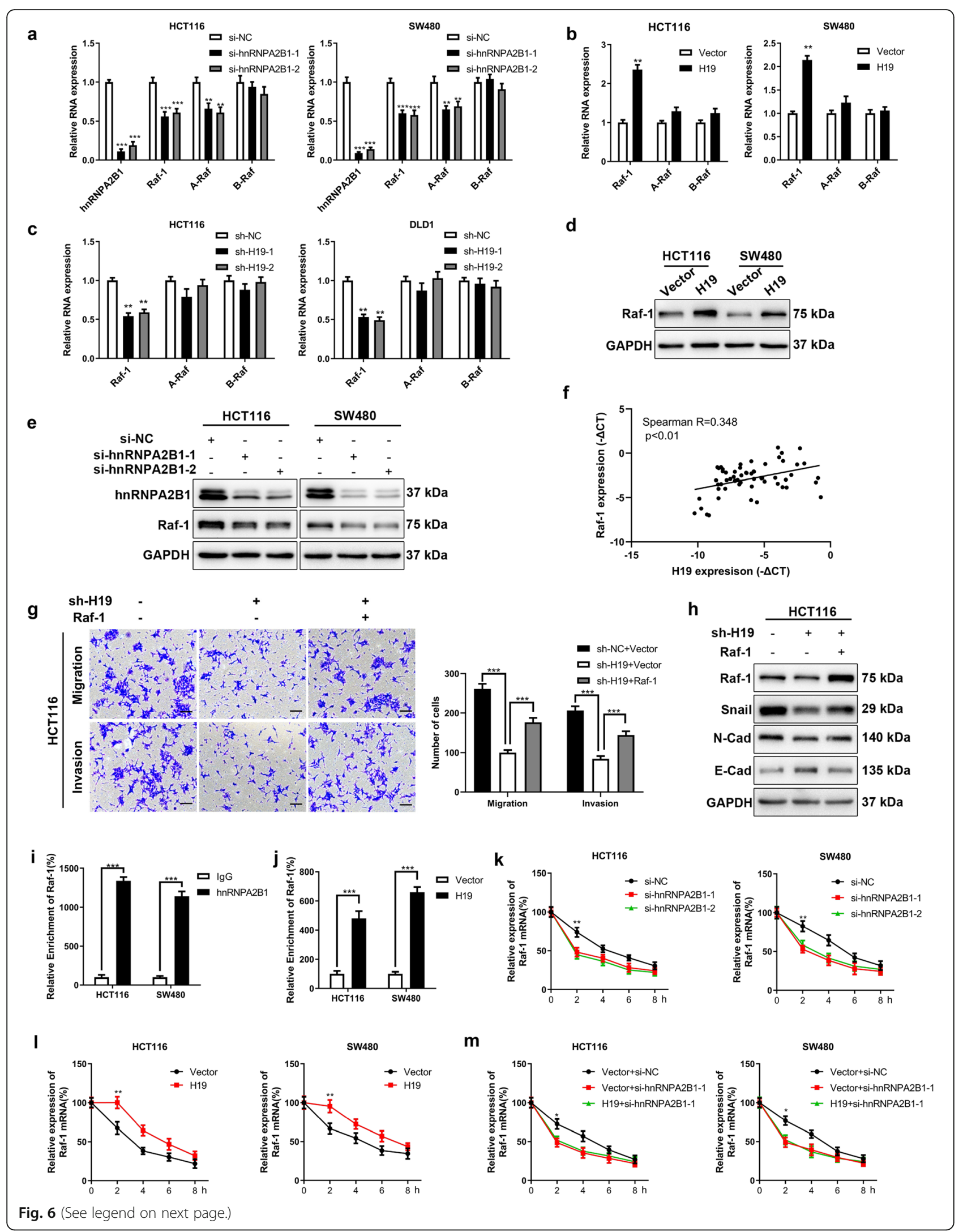


(See figure on previous page.)

Fig. 6 H19 stabilize RAF1 by interacting with hnRNPA2B1. a The effect of hnRNPA2B1 knockdown on the mRNA level of Raf kinase family was measured by qRT-PCR. $\mathbf{b}$ The influence of $\mathrm{H} 19$ overexpression on the mRNA level of Raf kinase family were measured by qRT-PCR in colorectal cancer cells. c The impact of $\mathrm{H} 19$ knockdown on the mRNA level of Raf kinase family were measured by qRT-PCR in colorectal cancer cells. $\mathbf{d}$ Western blot analysis of Raf-1 in H19 stable overexpression or control cells. e Western blot analysis of Raf-1 after hnRNPA2B1 knockdown in HCT116 and SW480 cells. f Correlation analysis of H19 and Raf-1 in primary colorectal cancer tissues. $\mathbf{g}$ Overexpression of Raf-1 rescued the migration and invasion of H19depleted HCT116 cells. $\mathbf{h}$ Western blot analyses of EMT markers after overexpression of Raf-1 in H19-depleted HCT116 cells. i RIP assay followed by qRT-PCR explored the enrichment of Raf-1 mRNA binding to hnRNPAA2B1. j RIP experiment showed that H19 overexpression increased the enrichment between Raf-1 mRNA and hnrnpA2B1. k Knockdown of hnRNPA2B1 disrupted the stability of Raf-1 mRNA compared with the control group. I Overexpression of $\mathrm{H} 19$ increased the stability of Raf-1 mRNA compared with the control group. $\mathbf{m}$ Knockdown of hnRNPA2B1 reversed H19induced Raf-1 mRNA stabilization. Student's t-test. ${ }^{*} P<0.05,{ }^{* *} P<0.01,{ }^{* *} P<0.001$

Nevertheless, the molecular mechanism of H19 to upregulate the metastatic capability of tumor cells in colorectal cancer were not clear. It is well established that EMT, a transition of cancer cells from epithelial phenotype to gain mesenchymal properties, is a prominent process for cancer metastases [39]. It has been reported that H19 affect EMT by functioning as miRNA sponges in breast cancer [18]. To further investigate the underlying mechanisms for H19 promoting migration and invasion of CRC cells, correlation analysis was performed according to the data in TCGA, and revealed that the expression of H19 is positively correlated with Snail, an EMT- transcription factor, which induce EMT by transcriptionally represses Ecadherin [40]. Our data suggested that ectopic expression of H19 increase the RNA and protein level of Snail, as well as $\mathrm{N}$-cadherin, and decreased the level of E-cadherin. Consistently, H19 knockdown downregulated the expression of Snail and N-cadherin, but increased the level of Ecadherin. Collectively, our study demonstrated that H19 can upregulate Snail expression, which subsequently induced EMT, and eventually promoted CRC metastasis in vitro and in vivo.
Mounting evidence showed that lncRNA act as key regulators by binding to RNA binding proteins (RBP). To explore the potential RBPs that H19 binds to, RNA pull-down assays and LC-MS were performed, and found that $\mathrm{H} 19$ binds to hnRNPA2B1 directly. HnRNPA2B1, a member of heterogeneous nuclear ribonucleoproteins mainly located in the nucleus, are of crucial importance for the stabilization of its target transcripts [34]. It has been reported that IncRNA can regulate the translocation of hnRNPs from nuclear to cytoplasm [30], leading to subsequent biological process in cancer [29]. Several studies have demonstrated cytoplasmic localization of hnRNPA2B1 is associated with oncogenesis [41, 42]. In present study, we found overexpression of H19 triggers the translocation of hnRNPA2B1 from nuclear to cytoplasm. Knockdown of hnRNPA2B1 alleviated the enhanced capability of migration and invasion caused by H19, as well as the expression of Snail, indicated a pivotal role of hnRNPA2B1 in H19-mediated EMT and metastasis. Ras/Raf/MEK/ERK signaling is always aberrantly activated and upregulate the expression of
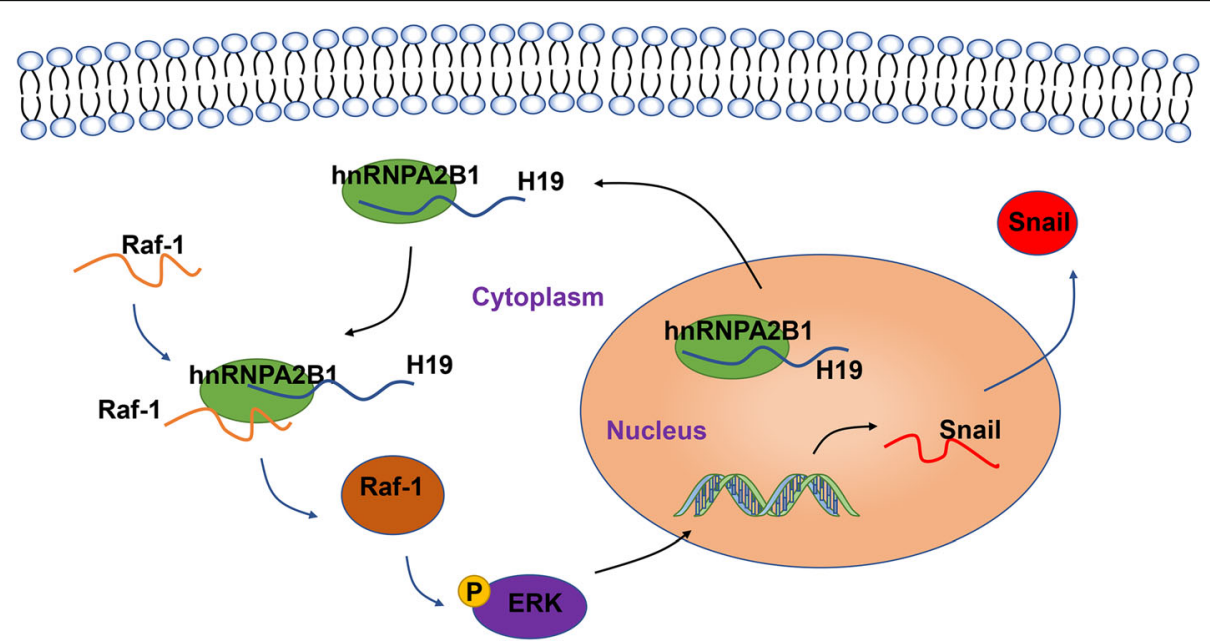

Fig. 7 Model of H19 interaction with hnRNPA2B1 and the signaling pathways involved in colorectal cancer metastasis. H19 interacts with hnRNPA2B1, promoting the translocation of hnRNPA2B1 from nucleus to cytoplasm, facilitating the binding between hnRNPA2B1 and Raf-1 mRNA, thereby stabilizing Raf-1 mRNA. Upregulation of Raf-1 activate ERK signaling pathways, thereby promoting the transcription of Snail and inducing EMT 
EMT transcript factors, consequently resulting in EMT and metastases in various types of cancers [33, 43, 44]. Our data demonstrated that the overexpression of H19 elevate the phosphorylation of ERK. Meanwhile, ERK signaling inhibitor blocked the upregulation of Snail caused by H19 overexpression, suggested H19 regulates the expression of Snail via ERK pathway. In addition, knockdown of hnRNPA2B1 attenuated the activation of ERK signaling induced by H19, which further confirmed hnRNPA2B1 work as downstream mechanism of $\mathrm{H} 19$ to promote EMT. To further elucidate the mechanism of ERK signaling activation, we found overexpression of $\mathrm{H} 19$ facilitates the binding between hnRNPA2B1 and the mRNA of Raf- 1 and consequently stabilizes Raf-1. Ectopic H19 expression upregulated the expression of Raf-1, subsequently activated Raf-ERK signaling. Overexpressed Raf- 1 rescued the migration, invasion and EMT in H19-depleted cells. In addition, hnRNPA2B1 knockdown reversed the effect of $\mathrm{H} 19$ on the stability of Raf-1, suggested H19 exert its functions dependent on hnRNPA2B1. Collectively, our study demonstrated the overexpression of $\mathrm{H} 19$ triggers the translocation of hnRNPA2B1 from nuclear to cytoplasm and increases the enrichment between hnRNPA2B1 and Raf-1 mRNA, consequently stabilizes and upregulates the expression of Raf-1, eventually leads to activation of Raf-ERK signaling and EMT (Fig. 7).

\section{Conclusions}

In conclusion, our finding reveals that lncRNA H19 is upregulated in colorectal cancer, and correlated with poor outcomes in CRC patients. By directly binding to hnRNPA2B1, H19 activates Raf-ERK signaling, resulting in the induction of EMT, and eventually promotes migration, invasion and metastasis of colorectal cancer cells. Our study discovers the critical role of H19 in mediating the pro-metastatic potential of CRC and highlight the potential of $\mathrm{H} 19$ acting as a prognostic predictor and therapeutic target for colorectal cancer.

\section{Supplementary information}

Supplementary information accompanies this paper at https://doi.org/10. 1186/s13046-020-01619-6.

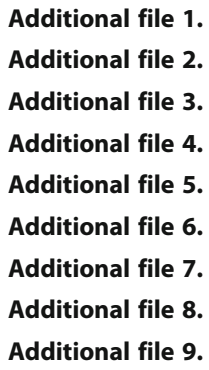

\section{Additional file 10}

Additional file 11: Table S1. Target sequences of siRNA Table S2. Target sequences of shRNA Table S3. Sequences of primers

Additional file 12: Table S4. Identifed the proteins binding to $\mathrm{H} 19$ by LC-MS

Additional file 13: Figure S1. The expression of $\mathrm{H} 19$ in different colorectal cancer cell lines detected by qRT-PCR. Figure S2. a The expression of H19 in HCT116 and SW480 cells after transfected with IV-H19 and control Iv-Vector to construct stable $\mathrm{H} 19$ overexpression cell lines. b The expression of H19 in HCT116 and DLD1 cells after transfected with sh-NC, sh-H19-1 and sh-H19-2 to construct stable H19 knockdown cell lines. Student's t-test. ${ }^{*} P<0.05,{ }^{* *} P<0.01,{ }^{* * *} P<0.001$ Figure S3. a Wound healing assay in HCT116 H19 stable overexpression and control. The relative migration rate is calculated compared to the distance of $0 \mathrm{~h}$. b Wound healing assay in H19 knockdown and control DLD1 cells. Scales bars $=250$ um. Student's t-test. ${ }^{*} P<0.05,{ }^{* *} P<0.01,{ }^{* * *} P<0.001$ Figure S4. a CCK-8 assays of $\mathrm{H} 19$ overexpression or control cells. b CCK-8 assays of H19 knockdown or control cells. Student's t-test. ${ }^{*} P<0.05$, ${ }^{* *} P<0.01$, *** $P<0.001$ Figure S5. Heatmap of the top 50 genes which H19 is most corelated with in TCGA database. Figure S6. a Effect of H19 overexpression on the mRNA level of EMT transcript factors in HCT116 and SW480 cells were measured by qRT-PCR. b Effect of H19 knockdown on the mRNA level of EMT transcript factors in HCT116 or DLD1 H19 cells were quantified by qRT-PCR. Figure S7. Agarose gel electrophoresis of RNA probe used for RNA pull-down assay. Figure S8. Immunofluorescence were performed to investigate the subcellular localization of hnRNPA2B1 in $\mathrm{H} 19$ depleted and control cells. Scales bars=10um. Figure S9. a Correlation analysis between $\mathrm{H} 19$ and hnRNPA2B1. b Correlation analysis between hnRNPA2B1 and Raf-1. Figure S10. RIP assay followed by qRT-PCR explored the enrichment of Raf-1 mRNA binding to hnRNPAA2B1 in H19 depleted and control cells. Student's t-test. ${ }^{*} P<0.05$, ${ }^{*} P<0.01$, ${ }^{* * *} P<$ 0.001

\section{Abbreviations}

IncRNA: Long non-coding RNA; CRC: Colorectal cancer; EMT: Epithelial-tomesenchymal transition; LC-MS: Liquid chromatography-mass spectrometry; hnRNPA2B1: Heterogeneous nuclear ribonucleoprotein A2/B1; qRT-

PCR: Quantitative real-time PCR; ERK: Extracellular signal-regulated kinase; RIP: RNA immunoprecipitation; IF: Immunofluorescence; Act-D: Actinomycin D; CCK-8: Cell Counting Kit-8; TCGA: The Cancer Genome Atlas; GSEA: Gene Set Enrichment Analysis; RBP: RNA binding protein

Conflict of interest

None of the authors have any competing financial interests.

Authors' contributions

YHZ, WBH and YLH designed the research. JW, WBH, JY, YHZ, YJY and JL performed the research. ZWW, $\mathrm{CHZ}$ and $\mathrm{YLH}$ analyzed the data and wrote the paper. All authors read and approved the final manuscript.

\section{Funding}

This study was supported by Science and Technology Project of Guangzhou (No. 201803040019), National Natural Science Foundation of China (No. 81702325) and Natural Science Foundation of Guangdong Province (No. 2017A030310565 and 2016A020213002).

Availability of data and materials

The datasets from the current study are available from the corresponding author on reasonable request. Publicly available data was obtained from the GEO database (https://www.ncbi.n/m.nih.gov/gds) and TCGA database (https://portal.gdc.cancer.gov/).

\section{Ethics approval and consent to participate}

The current study was performed with approval from the Ethics Committee of The First Affiliated Hospital, Sun Yat-sen University. All patients provided written informed consent. The animal experiments was performed under the approval of committee on the Ethics of Animal Experiments of The First Affiliated Hospital, Sun Yat-sen University. 


\section{Consent for publication}

All authors agree to submit the article for publication.

\section{Competing interests}

The authors declare that no competing interests.

Received: 23 March 2020 Accepted: 8 June 2020

Published online: 23 July 2020

\section{References}

1. Bray F, Ferlay J, Soerjomataram I, Siegel RL, Torre LA, Jemal A. Global cancer statistics 2018: GLOBOCAN estimates of incidence and mortality worldwide for 36 cancers in 185 countries. CA Cancer J Clin. 2018;68:394-424. https:// doi.org/10.3322/caac.21492.

2. Manfredi S, Lepage C, Hatem C, Coatmeur O, Faivre J, Bouvier A-M. Epidemiology and management of liver metastases from colorectal cancer Ann Surg. 2006;244:254-9. https://doi.org/10.1097/01.sla.0000217629.94941.cf.

3. Van Cutsem E, Cervantes A, Nordlinger B, Arnold D, Group EGW. Metastatic colorectal cancer: ESMO Clinical Practice Guidelines for diagnosis, treatment and follow-up. Ann Oncol. 2014;25(Suppl 3):iii1-9. https://doi.org/10.1093/ annonc/mdu260.

4. Rokavec M, Horst D, Hermeking H. Cellular model of Colon Cancer progression reveals signatures of mRNAs, miRNA, IncRNAs, and epigenetic modifications associated with metastasis. Cancer Res. 2017;77:1854-67. https://doi.org/10.1158/0008-5472.CAN-16-3236.

5. Ma M, Xu H, Liu G, Wu J, Li C, Wang X, et al. Metabolism-induced tumor activator 1 (MITA1), an energy stress-inducible long noncoding RNA, Promotes Hepatocellular Carcinoma Metastasis. Hepatology. 2019;70:215-30. https://doi.org/10.1002/hep.30602.

6. Ponting $\mathrm{CP}$, Oliver PL, Reik W. Evolution and functions of long noncoding RNAs. Cell. 2009;136:629-41. https://doi.org/10.1016/j.cell.2009.02.006.

7. Iyer MK, Niknafs YS, Malik R, Singhal U, Sahu A, Hosono Y, et al. The landscape of long noncoding RNAs in the human transcriptome. Nat Genet. 2015:47:199-208. https://doi.org/10.1038/ng.3192.

8. Adams BD, Parsons C, Walker L, Zhang WC, Slack FJ. Targeting noncoding RNAs in disease. J Clin Invest. 2017;127:761-71. https://doi.org/10.1172/ JCl84424.

9. Evans JR, Feng FY, Chinnaiyan AM. The bright side of dark matter: IncRNAs in cancer. J Clin Invest. 2016;126:2775-82. https://doi.org/10. $1172 / J C 184421$.

10. Rigoutsos I, Lee SK, Nam SY, Anfossi S, Pasculli B, Pichler M, et al. N-BLR, a primate-specific non-coding transcript leads to colorectal cancer invasion and migration. Genome Biol. 2017;18:98. https:/doi.org/10.1186/s13059-017-1224-0.

11. Fang C, Qiu S, Sun F, Li W, Wang Z, Yue B, et al. Long non-coding RNA HNF1A-AS1 mediated repression of miR-34a/SIRT1/p53 feedback loop promotes the metastatic progression of colon cancer by functioning as a competing endogenous RNA. Cancer Lett. 2017;410:50-62. https://doi.org/ 10.1016/j.canlet.2017.09.012.

12. Han P, Li JW, Zhang BM, LV JC, Li YM, Gu XY, et al. The IncRNA CRNDE promotes colorectal cancer cell proliferation and chemoresistance via miR181a-5p-mediated regulation of Wnt/beta-catenin signaling. Mol Cancer. 2017;16:9. https://doi.org/10.1186/s12943-017-0583-1.

13. Kong J, Sun W, Li C, Wan L, Wang S, Wu Y, et al. Long non-coding RNA LINC01133 inhibits epithelial-mesenchymal transition and metastasis in colorectal cancer by interacting with SRSF6. Cancer Lett. 2016;380:476-84. https://doi.org/10.1016/j.canlet.2016.07.015.

14. Ren J, Fu J, Ma T, Yan B, Gao R, An Z, et al. LncRNA H19-elevated LIN28B promotes lung cancer progression through sequestering miR-196b. Cell Cycle. 2018;17:1372-80. https://doi.org/10.1080/15384101.2018.1482137.

15. Wei Y, Liu Z, Fang J. H19 functions as a competing endogenous RNA to regulate human epidermal growth factor receptor expression by sequestering let-7c in gastric cancer. Mol Med Report. 2018;17:2600-6. https://doi.org/10.3892/mmr.2017.8184.

16. Ma L, Tian X, Guo H, Zhang Z, Du C, Wang F, et al. Long noncoding RNA H19 derived miR-675 regulates cell proliferation by down-regulating E2F-1 in human pancreatic ductal adenocarcinoma. J Cancer. 2018;9:389-99. https://doi.org/10.7150/jca.21347.

17. Vu T, Datta PK. Regulation of EMT in Colorectal Cancer: A Culprit in Metastasis. Cancers (Basel). 2017:9:pii: E171. doi:https://doi.org/10.3390/ cancers9120171.
18. Zhou W, Ye XL, Xu J, Cao MG, Fang ZY, Li LY, et al. The IncRNA H19 mediates breast cancer cell plasticity during EMT and MET plasticity by differentially sponging miR-200b/c and let-7b. Sci Signal. 2017;10:pii: eaak9557. doi:https://doi.org/10.1126/scisignal.aak9557.

19. De Craene B, Berx G. Regulatory networks defining EMT during cancer initiation and progression. Nat Rev Cancer. 2013;13:97-110. https://doi.org/ 10.1038/nrc3447.

20. Fan Y, Shen B, Tan M, Mu X, Qin Y, Zhang F, et al. TGF-beta-induced upregulation of malat 1 promotes bladder cancer metastasis by associating with suz12. Clin Cancer Res. 2014;20:1531-41. https://doi.org/10.1158/10780432.CCR-13-1455.

21. Yuan JH, Yang F, Wang F, Ma JZ, Guo YJ, Tao QF, et al. A long noncoding RNA activated by TGF-beta promotes the invasion-metastasis cascade in hepatocellular carcinoma. Cancer Cell. 2014;25:666-81. https://doi.org/10. 1016/j.ccr.2014.03.010.

22. Kim SK, Kim SY, Kim JH, Roh SA, Cho DH, Kim YS, et al. A nineteen genebased risk score classifier predicts prognosis of colorectal cancer patients. Mol Oncol. 2014;8:1653-66. https://doi.org/10.1016/j.molonc.2014.06.016.

23. Liberzon A, Birger C, Thorvaldsdottir H, Ghandi M, Mesirov JP, Tamayo P. The molecular signatures database Hallmark gene set collection. Cell Systems. 2015;1:417-25. https://doi.org/10.1016/j.cels.2015.12.004.

24. Alonso SR, Tracey L, Ortiz P, Perez-Gomez B, Palacios J, Pollan M, et al. A high-throughput study in melanoma identifies epithelial-mesenchymal transition as a major determinant of metastasis. Cancer Res. 2007;67:345060. https://doi.org/10.1158/0008-5472.Can-06-3481.

25. Gotzmann J, Fischer ANM, Zojer M, Mikula M, Proell V, Huber H, et al. A crucial function of PDGF in TGF-beta-mediated cancer progression of hepatocytes. Oncogene. 2006;25:3170-85. https://doi.org/10.1038/sj.onc. 1209083.

26. Hu WL, Jin L, Xu A, Wang YF, Thorne RF, Zhang XD, et al. GUARDIN is a p53-responsive long non-coding RNA that is essential for genomic stability. Nat Cell Biol. 2018;20:492-502. https://doi.org/10.1038/s41556-018-0066-7.

27. Zhang Y, He Q, Hu Z, Feng Y, Fan L, Tang Z, et al. Long noncoding RNA LINP1 regulates repair of DNA double-strand breaks in triple-negative breast cancer. Nat Struct Mol Biol. 2016;23:522-30. https://doi.org/10.1038/nsmb.3211.

28. Wu Y, Yang $X$, Chen $Z$, Tian $L$, Jiang $G$, Chen F, et al. $m$ (6) A-induced IncRNA RP11 triggers the dissemination of colorectal cancer cells via upregulation of Zeb1. Mol Cancer. 2019;18:87. https://doi.org/10.1186/ s12943-019-1014-2.

29. van Oordt WW, Diaz-Meco MT, Lozano J, Krainer AR, Moscat J, Caceres JF. The MKK3/6-p38-signaling cascade alters the subcellular distribution of hnRNP A1 and modulates alternative splicing regulation. J Cell Biol. 2000; 149:307-16. https://doi.org/10.1083/jcb.149.2.307.

30. Jiang $\mathrm{H}$, Wang $\mathrm{Y}$, Ai $\mathrm{M}$, Wang $\mathrm{H}$, Duan $\mathrm{Z}$, Wang $\mathrm{H}$, et al. Long noncoding RNA CRNDE stabilized by hnRNPUL2 accelerates cell proliferation and migration in colorectal carcinoma via activating Ras/MAPK signaling pathways. Cell Death Dis. 2017;8:e2862. https://doi.org/10.1038/cddis.2017.258.

31. Dai S, Zhang J, Huang S, Lou B, Fang B, Ye T, et al. HNRNPA2B1 regulates the epithelial-mesenchymal transition in pancreatic cancer cells through the ERK/snail signalling pathway. Cancer Cell Int. 2017;17:12. https://doi.org/10. 1186/s12935-016-0368-4.

32. Shilo A, Ben Hur V, Denichenko P, Stein I, Pikarsky E, Rauch J, et al. Splicing factor hnRNP A2 activates the Ras-MAPK-ERK pathway by controlling a-Raf splicing in hepatocellular carcinoma development. RNA. 2014;20:505-15. https://doi.org/10.1261/rna.042259.113.

33. Eblen ST. Extracellular-regulated kinases: signaling from Ras to ERK substrates to control biological outcomes. Adv Cancer Res. 2018;138:99-142. https://doi.org/10.1016/bs.acr.2018.02.004.

34. Goodarzi H, Najafabadi HS, Oikonomou P, Greco TM, Fish L, Salavati R, et al. Systematic discovery of structural elements governing stability of mammalian messenger RNAs. Nature. 2012;485:264-8. https://doi.org/10. 1038/nature11013.

35. Huarte M. The emerging role of IncRNAs in cancer. Nat Med. 2015;21:125361. https://doi.org/10.1038/nm.3981.

36. Chen JS, Wang YF, Zhang XQ, LV JM, Li Y, Liu XX, et al. H19 serves as a diagnostic biomarker and up-regulation of $\mathrm{H} 19$ expression contributes to poor prognosis in patients with gastric cancer. Neoplasma. 2016;63:223-30. https://doi.org/10.4149/207_150821n454.

37. Chen S-W, Zhu J, Ma J, Zhang J-L, Zuo S, Chen G-W, et al. Overexpression of long non-coding RNA H19 is associated with unfavorable prognosis in patients with colorectal cancer and increased proliferation and migration in 
colon cancer cells. Oncol Lett. 2017;14:2446-52. https://doi.org/10.3892/ol. 2017.6390.

38. Fellig Y, Ariel I, Ohana P, Schachter P, Sinelnikov I, Birman T, et al. H19 expression in hepatic metastases from a range of human carcinomas. J Clin Pathol. 2005;58:1064-8. https://doi.org/10.1136/jcp.2004.023648.

39. Lo HC, Zhang XH. EMT in metastasis: finding the right balance. Dev Cell. 2018;45:663-5. https://doi.org/10.1016/j.devcel.2018.05.033.

40. Nakaya Y, Sheng G. Epithelial to mesenchymal transition during gastrulation: an embryological view. Develop Growth Differ. 2008;50:755-66. https://doi. org/10.1111/j.1440-169X.2008.01070.x.

41. Jing G-J, Xu D-H, Shi S-L, Li Q-F, Wang S-Y, Wu F-Y, et al. Aberrant expression and localization of hnRNP-A2/B1 is a common event in human gastric adenocarcinoma. J Gastroenterol Hepatol. 2011;26:108-15. https:// doi.org/10.1111/j.1440-1746.2010.06482.x.

42. Cui H, Wu F, Sun Y, Fan G, Wang Q. Up-regulation and subcellular localization of hnRNP A2/B1 in the development of hepatocellular carcinoma. BMC Cancer. 2010;10:356. https://doi.org/10.1186/1471-2407-10-356.

43. Steelman LS, Abrams SL, Whelan J, Bertrand FE, Ludwig DE, Basecke J, et al. Contributions of the Raf/MEK/ERK, PI3K/PTEN/Akt/mTOR and Jak/STAT pathways to leukemia. Leukemia. 2008;22:686-707. https://doi.org/10.1038/ leu.2008.26.

44. Lamouille S, Xu J, Derynck R. Molecular mechanisms of epithelialmesenchymal transition. Nat Rev Mol Cell Biol. 2014;15:178-96. https:/doi. org/10.1038/nrm3758.

\section{Publisher's Note}

Springer Nature remains neutral with regard to jurisdictional claims in published maps and institutional affiliations.

Ready to submit your research? Choose BMC and benefit from:

- fast, convenient online submission

- thorough peer review by experienced researchers in your field

- rapid publication on acceptance

- support for research data, including large and complex data types

- gold Open Access which fosters wider collaboration and increased citations

- maximum visibility for your research: over $100 \mathrm{M}$ website views per year

At $\mathrm{BMC}$, research is always in progress.

Learn more biomedcentral.com/submissions 